\title{
Respiratory therapists: the unnoticed warriors during COVID-19 pandemic in India
}

\author{
Mrudula M. Sawadkar, M.Sc RT ${ }^{1}$, Varun R. Nayak, M.Sc RT ${ }^{1}$
}

MM Sawadkar, VR Nayak. Respiratory therapists: the unnoticed warriors during COVID-19 pandemic in India. Can J Respir Ther 2020;56:57. doi: $10.29390 /$ cjrt-2020-044.

Key Words: respiratory therapist; frontline warriors; Indian RT; COVID-19 pandemic

\section{Dear Editor,}

The novel coronavirus (COVID-19) pandemic has emerged as the biggest health care crisis, affecting more than 200 countries worldwide. As per the World Health Organization (WHO), more than 30 million cases had been reported globally by mid-September 2020 [1]. India is one of the highly affected countries, and the number of cases is still rising drastically, with current active cases reaching 5 million. As a health care crisis, this pandemic requires support from all health care workers. Along with the known health care communities like doctors and nurses, Respiratory Therapists (RTs) are working selflessly in tackling this situation.

In India, the RT profession has been recognized for 25 years and is still an emerging allied health profession [2]. Based on the estimation of the Human Resource Development Survey, around 12 universities offer RT programs and more than 1000 RTs have been trained since 1995 [3]. According to Shevade et al. [4], RTs are working in different locations throughout India, predominantly in South India. We work alongside doctors in areas like intensive care units (ICU), emergency departments, out-patient departments, and home care settings providing essential respiratory care services tailored for a vivid group of patients.

During the COVID-19 pandemic, approximately 10\%-20\% of the total diagnosed cases require ICU admission, and around 3\%-10\% of them require airway management and mechanical ventilation [5]. Trained staff called "frontline warriors," such as doctors, nurses, and RTs are required to perform these skills. We have observed that on average a working RT spends around $4-10 \mathrm{~h}$ per day treating COVID19 patients. According to the opinion of the working RTs in India, even if the working hours are not extended, wearing personal protective equipment and performing intense skills makes it exhaustive. It is also proven that the burnout levels are significantly higher among these frontline warriors in India [6]. The most stressful environment is in the ICU and high-dependency units of the hospital where the RT's work is vital.

Globally, the RT profession is not only well established but also is well recognized. The American Association of Respiratory Care (AARC) and Canadian Society of Respiratory Therapists (CSRT) are the two major bodies working for the benefits and expansion of this community.

\begin{abstract}
"Respiratory therapists sacrifice and dedicate themselves to helping their patients and their communities during this time of COVID-19," said Tom Kallstrom, AARC Executive Director [7]. He also added by saying, "Now, more than ever before, the role of the respiratory therapist is vital to the health of our nation." These encouraging words motivate RTs working to fight against COVID-19.

The Indian Association of Respiratory Care (IARC) is striving hard to portray the hard work done by RTs throughout India and on international grounds. Even after working selflessly, the RT profession remains unrecognized in various aspects like individual safety, work profile, and even as a part of the health care team. With this short article, we appeal to be noticed by all the major health care communities and given opportunities to prove our knowledge and skills. With this appeal, as an RT community, we promise to do our level best as frontline warriors in this time of crisis.
\end{abstract}

\section{REFERENCES}

1. Available at: https://covid19.who.int/WHO Coronavirus Disease (COVID-19) Dashboard.

2. Seedharan JK, Varghese S. Twenty-five years of excellence; respiratory therapy in India - past, present, and future. Indian J Respir Care 2020;9:5-11. https://doi.org/10.4103/ijrc.ijrc_62_19.

3. Ministry of Human Resource Development, Department of Higher Education. All India survey on higher education. 2019. Available at: https://mhrd.gov.in/aishe-report-2018-19 (Accessed April 25, 2020).

4. Shevade MS, Yeravdekar RC, Salvi SS. A cross-sectional survey of practice patterns and selected demographics of respiratory therapists in India. Respiratory Care 2020 Aug 18. https://doi.org/10.4187/ respcare.07823.

5. Mehta Y, Chaudhry D, Abraham OC, et al. Critical care for COVID-19 affected patients: position statement of the Indian society of critical care medicine. Indian J Crit Care Med 2020 Apr;24(4):222. https://doi. org/10.5005/jp-journals-10071-23395.

6. Khasne RW, Dhakulkar BS, Mahajan HC, Kulkarni AP. Burnout among healthcare workers during COVID-19 pandemic in India: Results of a questionnaire-based survey. Indian J Crit Care Med 2020;24(8):664-71. https://doi.org/10.5005/jp-journals-10071-23518.

7. Available at: https://www.aarc.org/nn20-respiratory-therapists-warriorsin-the-fight-against-covid-19/.

\footnotetext{
${ }^{1}$ Department of Respiratory Therapy, Manipal College of Health Professions, Manipal Academy of Higher Education, Manipal, Karnataka, India

Correspondence: Varun R. Nayak, M.Sc RT, Department of Respiratory Therapy, Manipal College of Health Professions, Manipal Academy of Higher Education, Manipal, Karnataka, India-576104. Tel.: +919972381165, E-mail: varunr838@gmail.com
}

Published online at https://www.cjrt.ca on 30 October 2020 